\title{
AGENTES DE DEGRADAÇĀO RELACIONADOS AOS PROJETOS DE ENGENHARIA
}

\author{
OLIVEIRA, VALÉRIA \\ Prof. ${ }^{\text {a }}$ Msc. Engenheira Civil \\ Doutoranda/PGGEC \\ Universidade do Vale dos Sinos \\ Rio Grande do Sul; Brasil \\ valeria.oliveira@ifro.edu.br
}

\author{
OLIVEIRA, FRANCIELE \\ Engenheira Civil \\ Mestranda /PPGEC \\ Universidade do Vale dos Sinos \\ Rio Grande do Sul; Brasil \\ fran.civil@gmail.com
}

\author{
MELO, RORENNYCHOLLAS \\ Engenheiro Civil \\ Mestrando /PPGEC \\ Universidade do Vale dos Sinos \\ Rio Grande do Sul; Brasil \\ rore_jiu@hotmail.com
}

\author{
ZANOLLA, IEDA \\ Engenheira Civil Esp. Patologia das Obras Civis \\ Mestranda /PPGEC \\ Universidade do Vale dos Sinos \\ Rio Grande do Sul ; Brasil \\ ieda.zanolla@gmail.com
}

\author{
PEIXOTO, MARIA ELIANA \\ Engenheira Civil \\ Universidade Federal do Ceará \\ Ceará; Brasil \\ elianasjr@hotmail.com

GRINGS, KÁTIA
Arquiteta e Urbanista
Mestranda PPGEC
Universidade do Vale dos Sinos
Rio Grande do Sul; Brasil
katiajocasta@gmail.com \\ GRINGS, KÁTIA \\ Arquiteta e Urbanista \\ Mestranda PPGEC \\ Rio Grande do Sul; Brasi \\ katiajocasta@gmail.com
}

Especialista Avaliações e Perícias de Engenharia

\section{RESUMO}

A redução do desempenho de um sistema construtivo ocorre devido à atuação de um ou de vários agentes de degradação. O objetivo deste estudo foi associar agentes de degradação à concepção dos projetos de engenharia que causam anomalias construtivas. A metodologia proposta é o mapeamento e revisão sistêmica da literatura e estudos de casos relacionados. São exemplos de incompatibilidade entre projetos e prevenção contra os agentes de degradação; a corrosão causada pelo contato entre metais dissimilares ou estresse causado por diferentes coeficientes de expansão térmica de componentes dissimilares rigidamente conectados; a não inclusão de componentes de estanqueidade em esquadrias; não detalhamento do elemento de acabamento na parte superior de janelas; a falta da previsão de ralos antientupimentos nas descidas de calhas. Desta forma, através da análise e mapeamento em projetos de engenharia relaciona-se as anomalias construtivas ocorridas em virtudes dos erros de concepção em projetos. Os estudos também apontam as condições de exposição e localização geográfica das edificações de forma a associar as anomalias aos fatores de danos. Desta forma, conclui-se que há necessidade de aplicar estudos multiescala no que se refere as anomalias construtivas, além de reconhecer que muitas das manifestações patológicas advêm da falta de projetos complementares e multidisciplinares entre si, que interajam os sistemas de forma conjunta e não isoladas.

Palavras-chave: degradação, projetos de engenharia, agentes de degradação.

\begin{abstract}
The reduction in the performance of a construction system occurs due to the action of one or more degradation agents. The aim of this study was to associate degradation agents to the design of engineering projects that cause construction anomalies. The proposed methodology is the mapping and systemic review of the literature and related case studies. Examples of incompatibility between projects and prevention against degradation agents; corrosion caused by contact between dissimilar metals or stress caused by different coefficients of thermal expansion of rigidly connected dissimilar components; the non-inclusion of sealing components in frames; no detailing of the finishing element in the upper part of windows; the lack of prediction of anti-clogging drains when going down the gutters. In this way, through the analysis and mapping in engineering projects, the construction anomalies related to design errors in projects are presented. The studies also point out the conditions of exposure and geographic location of the buildings in order to associate the anomalies to the damage factors. Thus, it is concluded that there is a need to apply multiscale studies with regard to constructive anomalies, in addition to recognizing that many of the pathological manifestations result from the
\end{abstract}


lack of complementary and multidisciplinary projects among themselves, that interact the systems in a joint and not isolated way.

Keywords: degradation, engineering projects, degradation agents.

\section{AGENTES DE DEGRADAÇÃO}

A ABNT NBR 15575-1 (2013) define agente de degradação tudo aquilo que agindo sobre um sistema contribui para reduzir seu desempenho. Observa-se a atuação conjunta de vários agentes de degradação que produzem ciclos sucessivos de causa-efeito, dificultando a identificação dos mecanismos de degradação atuantes, sejam reações químicas, mecânicas ou físicas que afetam as propriedades críticas dos elementos do edifício (OLIVEIRA et al., 2016). A origem dos agentes de degradação quando se trata do exterior das edificações são inicialmente climáticos, enquanto no interior; está relacionada com a ocupação, projeto e instalações. No entanto, um agente agindo externamente pode ocasionar degradações internas.

A exposição da edificação aos fatores de degradação, tais como a exposição ambiental e biológica, erros de concepção, erros de utilização e manutenção inadequada favorecem o surgimento de uma sequência de alterações nas características químicas, físicas ou mecânicas do elemento. Desta forma para determinar a degradação faz-se necessário conhecer com rigor os mecanismos, e a sequência de alterações prejudiciais ao elemento avaliado (OLIVEIRA et al., 2016).

A ISO 6241 (1984) classifica os agentes de degradação conforme a tabela 1. A classificação implica que sejam listados de acordo com sua própria natureza e não de acordo com a ação nos edifícios; por exemplo, um agente térmico pode ter uma ação física (expansão térmica) ou uma ação química (catálise). Exemplos de agentes mecânicos são cargas estáticas e dinâmicas do vento, gelo e tráfego, considerando que a temperatura e a radiação solar representam principalmente agentes térmicos e eletromagnéticos, respectivamente. Também, a água, solventes, agentes oxidantes e redutores, poluentes gasosos e particulados podem servir como exemplos de categorias de agentes químicos de degradação.

Tabela 1 - Agentes de Degradação.

\begin{tabular}{c|c}
\hline Natureza & Classe \\
\hline Mecânicos & Gravitacional; forças e deformaços impostas e restringidas, energia cinética, \\
& vibrações e ruídos \\
\hline Eletromagnéticos & Radiação, eletricidade e magnetismo \\
\hline Térmicos & Elevados níveis e gradientes de temperaturas \\
\hline Químicos & Água, solventes, oxidantes, redutores, ácidos, bases, sais \\
\hline Biológicos & Vegetais, microrganismos e animais \\
\hline
\end{tabular}

Fungos e bactérias são importantes agentes ambientais que podem causar deterioração de materiais, como calcário e arenito, quando se aumenta o tempo de umidade e ocorre a produção de compostos ácidos. Já um agente químico como a água pode ter uma ação física (expansão) ou uma ação química (dissolução da hidratação). Além disso, os agentes em combinação podem ter ações físicas adicionais (ciclos de molhagem e secagem), ações químicas (foto-oxidação pelo oxigênio atmosférico e radiação solar) ou ações biológicas (disseminação de raízes em alta umidade). Souza et al. (2017) incluem as variáveis atmosféricas conforme a tabela 2.

Tabela 2 - Degradação causada nas construções pelas variáveis atmosféricas.

\begin{tabular}{c|c}
\hline Variável atmosférica & Quebra das ligações poliméricas \\
\hline Radiação solar & Variação volumétrica de materiais e geração de fissuras por fadiga. \\
\hline Temperatura do ar & Veículo de transporte de sais e $\mathrm{CO}_{2}$. \\
\hline Umidade do ar & Na forma de condensação podem gerar ambiente propício para o crescimento de \\
& micoorganismos biológicos. \\
\hline Precipitação & $\begin{array}{c}\text { Veículo de transporte de sais e } \mathrm{CO}_{2} . \\
\text { A intensidade pode gerar lixiviação de alguns materiais. }\end{array}$ \\
\hline Vento & Velocidade, direção e sentido podem causar movimentações da edificação. \\
\hline
\end{tabular}
Fonte: Adaptada de Souza et al. (2017). 
O objetivo deste estudo foi associar agentes de degradação à concepção dos projetos de engenharia que causam anomalias construtivas.

\section{AGENTES DE DEGRADAÇÃO RELACIONADOS AOS PROJETOS DE ENGENHARIA}

Lersch (2003) explica que as características de uma edificação podem determinar um grau maior ou menor de degradação; relacionadas à implantação da edificação no terreno, aos materiais e às técnicas construtivas empregadas. Portanto o processo de degradação se inicia logo após a conclusão da construção das edificações e depende das condições de exposição, qualidade do projeto, manutenções e características do edifício, de forma que a mesma contribui para a diminuição da vida útil (SANTOS, 2017).

A incompatibilidade entre os materiais construtivos ou a visão sistêmica do edifício são considerados agentes relacionados ao projeto. Por exemplo, corrosão causada pelo contato entre metais dissimilares ou estresse causado por diferentes coeficientes de expansão térmica de componentes dissimilares rigidamente conectados; a não inclusão de componentes de estanqueidade em esquadrias; não detalhamento do elemento de acabamento na parte superior de janelas, a falta da previsão de ralos anti-entupimentos (ralo hemisférico) nas descidas de calhas são exemplos de incompatibilidade entre projetos e prevenção contra os agentes de degradação.

A colocação de aparelhos de ar condicionado após a entrega da obra de forma inadequada ou a fixação em locais que poderão danificar tubulações, revestimentos e pinturas; também configuram agentes de degradação ocasionados por erros de concepção de projetos.

Devem igualmente considerar-se aspectos de projeto no dimensionamento das estruturas de concreto armado, evitando que se desenvolvem mecanismos de degradação no início da vida útil da estrutura. A forma dos elementos estruturais deve ser tal que conduza a uma drenagem adequada evitando a saturação do concreto (RODRIGUES, 2011). Será, portanto, conveniente evitar a concepção de superfícies horizontais ou utilizar sistemas de proteção adicional, sobretudo em zonas submetidas a ciclos de molhagem/secagem.

Silva (2014), em Brasília - DF, representou as curvas de degradação definidas através do estudo de várias anomalias ao longo do tempo, através da comparação do estado de conservação em cento e vinte quatro casos de edifícios com revestimentos pétreos, com diferentes idades.

A Figura 1 mostra curvas de evolução da degradação em função da orientação da fachada da edificação (Norte, Leste Sul e Oeste) obtidas por Silva (2014), onde os resultados permitiram comprovar a influência da localização do edifício na evolução e aceleração da deterioração, pois identificou-se com precisão os diferentes níveis de degradação em relação à idade, evidenciando maior intensidade de degradação para os edifícios com idades superiores a 10 anos e processo evolutivo de degradação, principalmente nas idades superiores a 30 anos, sendo mais evidente em relação à orientação mais crítica (Oeste).

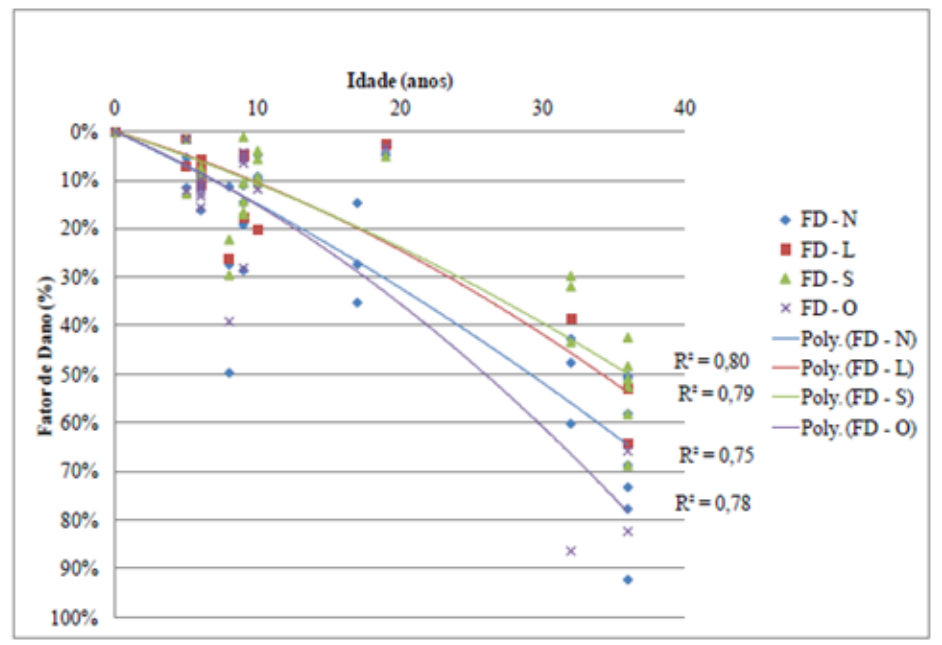

Figura 1: Curvas de evolução da degradação em função da orientação da edificação. Fonte: Adaptada de Silva (2014). 
Falhas originadas na fase de estudos preliminares ou anteprojetos acarretam em processos construtivos a custos mais elevados ou gerar transtornos na fase de utilização da obra, e as falhas geradas no processo de concepção do projeto final de engenharia podem criar manifestações patológicas (SOUZA E RIPPER, 1998), tais como: Falta de compatibilização de projetos (arquitetônicos, estruturais, hidráulicos, elétricos etc.); má especificação de materiais; detalhamentos incorretos ou insuficientes; erros de dimensionamento e até má definição de concepções estruturais, erro de dimensionamento de cargas atuantes.

Um exemplo de falhas são fissuras que podem começar a surgir, de forma congênita,logo no projeto arquitetônico da construção, pois s profissionais ligados ao assunto devem se conscientizar de que muito pode ser feito para minimizar o problema, pelo simples fato de reconhecer que as movimentações dos materiais e componentes das edificações civis são inevitáveis (VIDAL, 2012).

\section{MÉTODOS}

A metodologia proposta é o mapeamento e revisão sistêmica da literatura envolvendo estudos de caso relacionados aos erros de concepção em projetos de engenharia que motivaram anomalias construtivas. As pesquisas foram levantadas em teses, dissertações e artigos no site google acadêmico. As palavras chaves utilizadas na busca foram anomalias, patologias e danos em estruturas, revestimentos, fachadas e esquadrias relacionadas aos erros de projeto.

\section{RESULTADOS}

\subsection{Estruturas de concreto}

Conforme a Eurocódigo 2, NP EN 1992-1-1 (2010), uma estrutura de concreto deve atender a alguns requisitos como resistência, estabilidade durante a vida útil da estrutura e sem precisar de grandes manutenções. A norma determina que a vida útil de uma estrutura de concreto é 50 anos, e para isso é preciso levar em consideração a agressividade ambiental e a sua interação com a estrutura, onde é necessário conhecer as características do concreto como seu cobrimento, a através do cobrimento é possível verificar se é necessário fazer adaptações na armadura como a utilização de armaduras de aço inox ou adaptar a proteção superficial da estrutura.

Cabral e Campos (2016) estudaram sobre a alta agressividade do ar atmosférico da cidade de Fortaleza, assim , os autores verificaram que na cidade, o comportamento da agressividade é diferente em função da direção dos ventos. Os valores de deposição de cloretos da região da Praia do Futuro foram os mais elevados quando comparados aos de outras cidades brasileiras e estrangeiras. Além, disso observaram que a taxa de deposição de íons cloreto tem um descréscimo exponencial, à medida que se afastam do mar, e que a partir de 500 m a 1000 m estes teores são similares para as duas regiões da cidade de estudo.

Uma proposta dos autores no que se refere ao estudo das anomalias na fase de projeto trata da delimitação da classe de agressividade ambiental variar não apenas em função da região da cidade mas também em função dos tipos e características dos materiais utilizados na estrutura. Como exemplo, uma estrutura a ser construída na região da Praia do Futuro, a $900 \mathrm{~m}$ de distância do mar se for construída com um concreto utilizando cimento CP IV, estará situada na zona de agressividade classe II (Moderada), podendo utilizar cobrimentos de $25 \mathrm{~mm}$ para lajes e $30 \mathrm{~mm}$ para vigas e pilares. Já se for construída com concreto que utilizado o cimento CP II F, a mesma edificação estará situada na zona de agressividade classe III (Forte), devendo utilizar cobrimentos de $35 \mathrm{~mm}$ para lajes e $40 \mathrm{~mm}$ para vigas e pilares.

Esta diferença está relacionada principalmente devido às características distintas dos cimentos, onde o concreto produzido com o CP IV se apresentará com menor porosidade se comparado ao concreto produzido com o CP II F. Logo, para esta obra, se construída com cimento CP II F precisará atender requisitos para classe de agressividade III (Forte), com maiores cobrimentos nominais para as armaduras, gerando mais custos para a construção, enquanto que se construída com CP IV, precisará atender requisitos para a classe de agressividade II (Moderada), reduzindo o valor global da obra.

Recentemente ocorreu o desabamento de um edificio em Fortaleza por conta de corrosão em estrutura de pilares. Ainda, observa-se o problema com anomalias em lajes nervuradas, que por si só necessitam de um concreto menos poroso e da compatibilidade do cobrimento da armadura versus a espessura e altura das nervuras (figura 2), o que vem sendo muitas vezes não verificado em projetos estruturais. Poderia ser questionado se o erro não foi apenas construtivo, contudo 
observa-se que na prática há um erro de concepção estrutural tanto de seleção da classe de agressividade ambiental, quanto da seleção de materiais, definição do cobrimento sem visualizar a espessura da armadura.

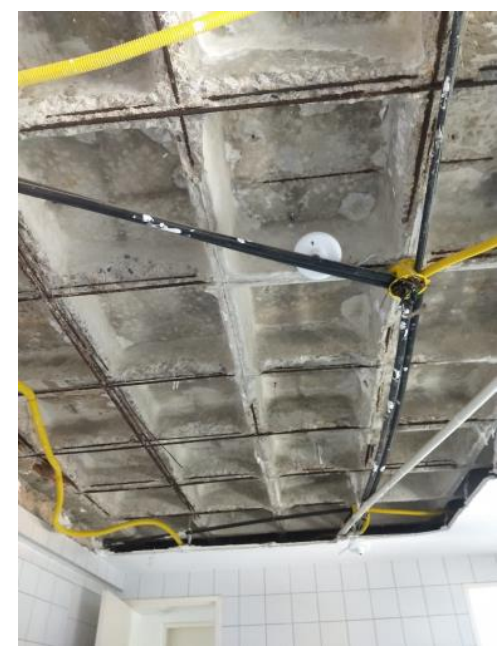

Figura 2: Lajes nervuradas com armadura em processo de corrosão. Fonte: Autores (2019).

O envelhecimento precoce das edificações é resultado da utilização de materiais com baixa qualidade; de erros e da falta de controle no projeto e na execução; da falta de manutenção e do desconhecimento da agressividade do meio ambiente em que a estrutura estará inserida (BATISTA, 2016).

Amorim (2010) relata que no caso de concretos aparentes, nas especificações de projetos não constam tipo e marca do cimento, o mesmo vale para os outros constituintes do concreto, a fim de obter uniformidade na aparência final desejada. Além disso, a água e os aditivos também podem influenciar a tonalidade do concreto, contudo só verificam a influência destes materiais no que se refere a resistência à compressão e o ataque as armaduras.

Em meios agressivos, os cantos e bordos devem ser arredondados reduzindo a possibilidade de acúmulo de agentes deletérios, no dimensionamento das armaduras deve ser evitado o congestionamento, ou seja, não permitir a concentração de barras de aço muito próximo umas das outras, para não ocorrerem falhas no adensamento (SILVA, 1995, AMORIM, 2010). Outro destaque dos autores trata do uso de pingadeiras nas bordas das vigas evitando o escoamento de água pela superfície do concreto, selar as juntas de dilatação, de forma a evitar quinas quebradas em elementos estruturais (figura 3 ).

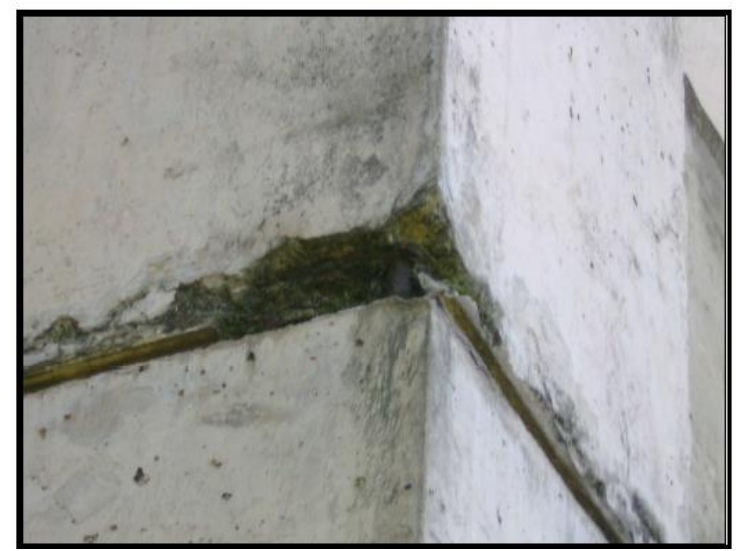

Figura 3: Quinas quebradas nas vigas de concreto. Fonte: Amorim (2010). 


\subsection{Fachadas}

No caso de fachadas, Gaspar e Brito (2005) identificaram que 25\% dos problemas de deterioração de fachadas de edifícios revestidos com argamassa de base cimentícia e pintura, materiais usuais no Brasil, foram decorrentes da chuva dirigida e do escorrimento superficial de água na fachada. Para Silva (2014), as fachadas devem ser adotados revestimentos pouco porosos e/ou ainda barreiras arquitetônicas para impedir a penetração de água, como pingadeiras, molduras, cimalhas, peitoris e frisos.

Becere (2007) elaborou uma tabela comparativa para os critérios de classificação do grau de agressividade do ambiente em que está inserido a edificação (Tabela 2) e uma outra para a categoria das fachadas quanto suas condições de exposição (tabela 3). O autor construiu os dados a partir dos trabalhos propostos por LACY (1971 apud CINCOTTO, SILVA; CASCUDO, 1995), por LIMA e MORELLI, (2005) e por UEMOTO (2002), uma vez que se mostraram congruentes.

Tabela 2 - Critérios de classificação do ambiente externo.

\begin{tabular}{|c|c|}
\hline Grau de agressividade do ambiente & Critério de classificação \\
\hline Fraco (baixo) & $\begin{array}{l}\bullet \quad \text { ICD }<3 \mathrm{~m} 2 / \mathrm{s}(1) ; \text { e/ou } \\
\text { - } \quad \text { Área afastada da orla marítima (mais de } 10 \mathrm{~km})(3) \text { e com } \\
\text { regime de chuva baixo (2) (3); e/ou } \\
\text { - Precipitações anuais menores que } 600 \mathrm{~mm} \text {, e para regiões } \\
\text { com índices de precipitação superiores que estejam muito } \\
\text { bem protegidas do vento (4). }\end{array}$ \\
\hline Moderado & 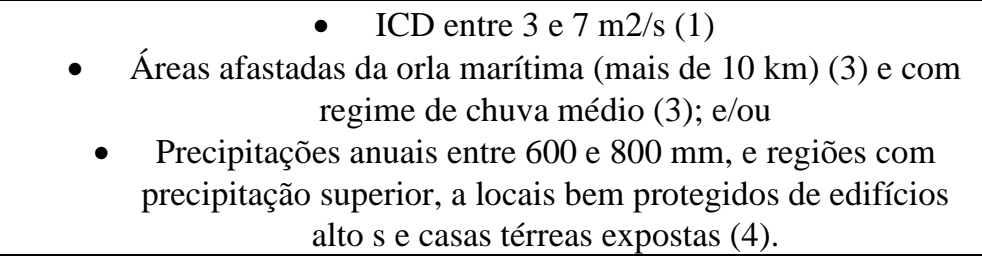 \\
\hline Intenso (severo) & $\begin{array}{c}\bullet \quad \operatorname{ICD}>7(1)(3) ; \text { e/ou; } \\
\text { - Área dentro da orla marítima (até } 3 \mathrm{~km})(3) \text {, áreas próximas a } \\
\text { grandes lagos ou estuários }(1), \text { e/ou; } \\
\text { - Regiões dentro da orla marítima (até } 8 \mathrm{~km})(1) \text { com regime } \\
\text { de chuva elevado e ventos fortes }(2) \text {, e/ou; } \\
\text { - Precipitações anuais acima de } 800 \mathrm{~mm}(4) \text { e regiões } \\
\text { Com índice de precipitação inferior, mas com alta incidência de } \\
\text { ventos (costas litorâneas, montanhas altas e médias) (4). }\end{array}$ \\
\hline
\end{tabular}

\section{1 - LACY (1971 apud CINCOTTO, SILVA; CASCUDO, 1995), MEDEIROS (1998); LIMA e MORELLI (2005); 2 - BS 5262 (BSI; 1991); 3 - BS 6150 (BSI, 1991) UEMOTO (2002); 4 - DIN 4108-3 (DIN, 2001)}

Fonte: Adaptada de Becere (2007).

Para Becere (2007), a especificação do sistema de proteção mais adequado às fachadas deverá considerar o grau de agressividade do ambiente externo e a categoria das fachadas quanto às suas condições de exposição. 
Tabela 3 - Classificação das fachadas quanto às suas condições de exposição.

\begin{tabular}{c|c}
\hline Categoria & Condições de exposição das fachadas \\
\hline Protegida & a) Edificações permanentes na vizinhança a protegem em todas as \\
& direções, possuem altura superior ao respaldo da parede equivalente a \\
1,2 vezes a distância horizontal que as separam ou ainda se existir & uma outra parede além do respaldo da parede em questão, cuja \\
& largura seja pelo menos 85\% da altura (1); e/ou
\end{tabular}

b) Paredes da edificação são protegidas das intempéries por detalhes construtivos do tipo beirais e pela proximidade de

Edifícios com altura igual ou superior (2). Nesta categoria são

inseridos os edifícios de baixa altura (até 2 pavimentos) em pequenas cidades (2).

Parcialmente protegida
Paredes da edificação são parcialmente protegidas das intempéries pela vizinhança de prédios de mesma altura e detalhes com instrutivos como os beirais de telhado (2). Neste grupo são classificados os edifícios localizados em pequenas cidades e regiões suburbanas (2).

Locais bem protegidos de edifícios altos e casas térreas expostas (3).

Exposta

Paredes da edificação são expostas às intempéries.

Inserem-se neste grupo os edifícios em locais abertos próximos à costa litorânea, assim como edifícios localizados bastante acima do nível norma 1 das demais edificações (1) (2).

Edifícios altos e expostos (3).

1 - LACY (1971 apud CINCOTTO, SILVA; CASCUDO, 1995), MEDEIROS (1998); LIMA e MORELLI (2005); 2 - BS 5262 (BSI, 1991); 3 - DIN 4108-3 (DIN, 2001).

Fonte: Adaptada de Bebere (2007).

Fontenelle e Moura (2004), Lucas e Abreu (2006) e Sousa (2008) alertam também para a influência dos erros de projeto e da ausência de manutenção no bom comportamento dos revestimentos cerâmicos aderentes. Sousa (2008) cita que a existência de controle de qualidade no projeto, o tipo de colagem, a classe do material de assentamento e de preenchimento de juntas, e a designação comercial do ladrilho são informações de difícil obtenção. A autora citou em seus estudos em edifícios com uma idade de 7 anos apenas, relativamente ao projeto, denotou-se uma incorreta prescrição dos materiais, tendo-se utilizado ladrilhos propensos a grandes variações dimensionais com juntas rígidas. Face a este erro, verificou-se que todas as reparações foram efetuadas sem preenchimento das juntas.

No caso de erros de concepção de projetos, Silvestre (2005) propôs uma classificação das causas de anomalias em revestimentos cerâmicos aderentes:

- Escolha de materiais incompatível, omissa, ou não adequada à utilização

- Estereotomia não conforme com as características do suporte

- Prescrição de colagem simples em vez de dupla

- Dimensionamento incorreto das juntas do revestimento cerâmico aderente

- Inexistência de juntas periféricas, de esquartelamento ou construtivas

- Existência de zonas do revestimento cerâmico aderente inacessíveis para limpeza

- Deficiente cuidado na pormenorização das zonas singulares do revestimento cerâmico aderente 
- Inexistência ou insuficiência de pendentes em pavimentos exteriores

- Inexistência ou anomalia dos elementos periféricos do revestimento cerâmico aderente

- Deformações excessivas do suporte

- Umidade ascensional do terreno

Oliveira et al. (2017) realizaram um levantamento quantitativo das principais manifestações patológicas identificadas nos revestimentos cerâmicos de fachadas de edifícios na cidade de São Paulo e obtiveram como resultado catorze edifícios, com idades entre 3 e 20 anos, apresentaram descolamentos originados, preponderantemente, por falhas de origem provenientes de irregularidades de projeto ou de execução, enquanto os outros dez, com idades entre 21 e 47 anos, apresentaram descolamentos originados, preponderantemente, por falhas de origem provenientes de ausência, insuficiência e/ou incorreta manutenção preventiva. Desta forma, os autores concluiram que as falhas com origem no projeto/execução foram significativamente maiores que as com origem em manutenções preventivas, contribuindo para evidenciar a importância do projeto e do domínio do processo construtivo deste tipo de revestimento.

Uma anomalia recorrente em fachadas ocorre também em locais de balanços estruturais, uma vez que não se inclui juntas de dilatação no encontro da viga estrutural com a alvenaria revestida com argamassa (figura 4), e assim, formamse trincas no revestimento e na pintura.

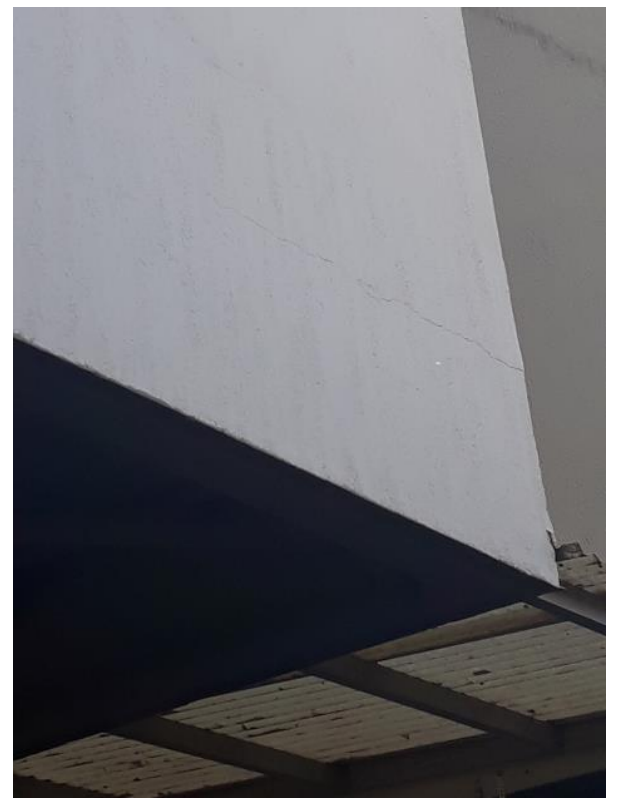

Figura 4: Trincas em revestimentos de fachadas. Fonte: Autores (2019).

Um problema recorrente trata da incompatibilidade de projetos de instalações de ar condicionado versus sistemas de pintura e instalações sanitárias. Estudos de casos mostram por exemplo, o estufamento da pintura observado próximo aos locais onde estão instalados os aparelhos de ar condicionado ou a ligação indevida do dreno do ar condicionado em tubos de ventilação ou tubulação sanitária. 


\subsection{Esquadrias}

As madeiras, além de porosas, são higroscópicas e por absorverem umidade, sofrem alteração dimensional provocando empenamentos. Já os metais ferrosos são altamente sensíveis à corrosão quando em contato com a umidade, o oxigênio e os elementos poluentes (POLITO, 2006).

Anomalias recorrentes pela falta de especificação e definição de vergas e contra-vergas em vãos de abertura e esquadrias que ocasionam fissuras em alvenarias e revestimentos (figura 5) são exemplos também de manifestações patológicas com origem em projetos (TEIXEIRA E SILVA, 2019).

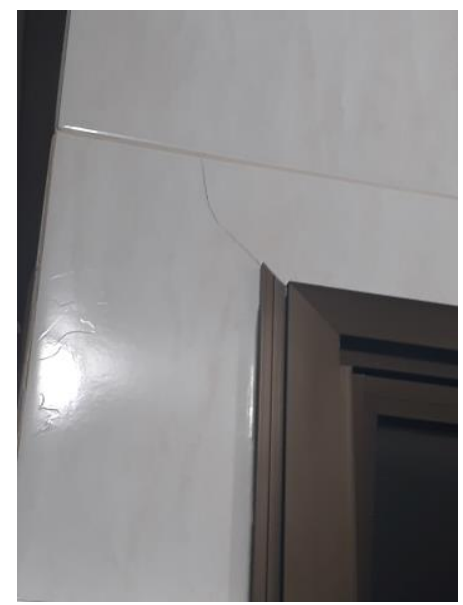

Figura 5: Trinca em revestimento cerâmico devido a falta de verga em vão de esquadrias. Fonte: Autores (2019).

Zucchetti (2016) estudou a problemática relacionada ao manchamento e infiltração de água na área próxima às janelas, assim a autora buscou identificar, com base em testes de chuva dirigida, a influência das características de projeção, com variações de $50 \mathrm{~mm}$ e $120 \mathrm{~mm}$, de inclinação, com valores de $6 \%$ e $20 \%$, e engaste lateral do peitoril, sem engaste e com engates de $100 \mathrm{~mm}$, no molhamento da área de fachada localizada próxima às janelas.

Os resultados da autora mostraram a interferência da definição de projeção de peitoris de forma a evitar manifestações patológicas e assim verificou que a utilização de prolongamentos laterais nos peitoris promoveram melhor desempenho dos modelos com relação ao descolamento da água da chuva das paredes, quando em comparação àqueles que não possuem esta configuração. No caso da inclinação dos peitoris identificou-se que o valor de $6 \%$ permite, mesmo com a existência de um lacrimal na face inferior do peitoril, a percolação da água da chuva pela porção inferior deste elemento, com um gotejamento vertical.

Já com $20 \%$ de inclinação do peitoril não se verifica este comportamento, contudo, o gotejamento ocorre no sentido da parede do modelo, direcionando parte do fluxo da chuva para a área localizada abaixo do peitoril, condicionando valores mais elevados de coleta de chuva. A projeção de $50 \mathrm{~mm}$ protege de forma menos eficiente as paredes dos modelos do molhamento pela chuva dirigida, gerando áreas protegidas menores e maiores valores de água coletada quando comparadas à projeção de 120 mm (ZUCCHETTI, 2016).

\subsection{Pinturas}

A especificação tardia dos produtos a serem utilizados sem levar em contar a análise técnica adequada, tem ressaltado a inexistência sistemática de projetos de sistemas de pinturas. Fagundes Neto (2007) cita que muitas vezes não é considerado o estudo do ambiente em que está inserido o edifício, as condições de utilização, além de outras variáveis fundamentais para a especificação adequada do produto a ser utilizado. Britez ((2007) comenta que o sistema de pintura é decidido de forma isolada dos demais sistemas construtivos e geralmente o critério de seleção é custo, sem nenhum critério técnico. Tal fato concorda com Polito (2006) que compreende que as especificações de pintura na construção civil devem ser feitas mediante pleno conhecimento das condições ambientais e dos diversos tipos de 
substratos. As pinturas a base de óleo de linhaça, por exemplo são consideradas mais afetadas pelo ataque de mofo do que as executadas em resinas sintéticas (CIB W80, 2004).

Mais de $90 \%$ das tintas a base de solvente usam resinas alquídicas (reação de álcoois polihidricos, como os glicóis e a glicerina, adicionando-se ácidos orgânicos como o maleic e o sebaic) como aglomerante que secam rapidamente e formam uma película dura, diferentemente dos óleos vegetais e resinas sintéticas. Portanto, estas tintas não devem ser aplicadas diretamente sobre paredes ou superfícies alcalinas, a não ser que se aplique um isolante resistente aos álcalis. De outra forma, ocorrerá a saponificação do veículo (POLITO, 2006).

Conforme o autor, a utilização de solventes inadequados, que não tenham poder de solvência sobre a resina, pode causar problemas nas tintas, como a coagulação ou precipitação da resina, perda de brilho, diminuição da resistência à água. Normalmente, são utilizados composições de solventes com diferentes pontos de ebulição, de maneira que os solventes " mais leves" formam a película logo após a aplicação, evitando o escorrimento, e os " mais pesados" possibilitam a correção de imperfeições como marcas de pincel e crateras. A Norma BS 6150:2019 - Painting of buildings. Code of practice apresenta diretrizes para a seleção de sistemas de pinturas tendo como fator determinante o grau de agressividade do meio ambiente. A tabela 4 apresenta os critérios para classificação do ambiente externo.

Tabela 4 - Classificação do grau de agressividade conforme o ambiente externo.

\begin{tabular}{|c|c|}
\hline $\begin{array}{c}\text { Grau de } \\
\text { agressividade }\end{array}$ & Ambiente externo \\
\hline Fraco & Área afastada da orla marítima (mais de $10 \mathrm{~km}$ ), não industrial e com regime de chuva baixo \\
\hline \multirow[b]{2}{*}{ Moderado } & a) Área próxima à orla marítima (de 3 a $10 \mathrm{~km})$, não industrial com regime de chuva médio. \\
\hline & $\begin{array}{l}\text { b) Área afastada da orla marítima (mais que } 10 \mathrm{~km} \text { ) urbana ou semi-industrial, com poluição } \\
\text { atmosférica média, mas afastada de fontes de poluição. }\end{array}$ \\
\hline \multirow[t]{2}{*}{ Severo } & $\begin{array}{l}\text { a) Área dentro da orla marítima (até } 3 \mathrm{~km} \text { ), não industrial, com regime de chuva elevado. } \\
\text { Áreas com índice de chuvas dirigidas (DRI) } \geq 7 .\end{array}$ \\
\hline & b) Área industrial, com poluição atmosférica elevada. \\
\hline Muito severo & Área dentro da orla marítima (até $3 \mathrm{~km}$ ) e com elevada poluição atmosférica. \\
\hline
\end{tabular}

Polito (2006) em seus estudos cita as principais anomalias ligadas aos sistema de pintura são aqueles causados pela interface do filme com o substrato da aplicação e outros na própria película da pintura. $\mathrm{O}$ autor listou as anomalias em pinturas; possíveis causas e soluções, conforme a tabela 5.

Tabela 5 - Anomalias e causas.

\begin{tabular}{|c|c|}
\hline Anomalias & Causas \\
\hline $\begin{array}{l}\text { Incompatibilidade de } \\
\text { tintas }\end{array}$ & $\begin{array}{l}\text { Uso de tinta base água sobre mais de três ou quatro camadas já existentes de tinta base óleo ou } \\
\text { alquídica envelhecidas faz com que as tintas velhas descolem do substrato. }\end{array}$ \\
\hline $\begin{array}{l}\text { Baixo poder de } \\
\text { cobertura }\end{array}$ & $\begin{array}{l}\text { Uso de uma tinta de baixa qualidade; Uso de pincel ou rolo de baixa qualidade; Uso de uma } \\
\text { combinação imprópria de base de tingimento e cor de tingimento; Pobre alastramento e } \\
\text { nivelamento da tinta; Uso de uma tinta muito mais clara que o substrato ou que contenha } \\
\text { pigmentos orgânicos de baixo poder de cobertura; Aplicação de tinta com taxa de } \\
\text { espalhamento maior que o recomendado }\end{array}$ \\
\hline $\begin{array}{l}\text { Escorrimento de } \\
\text { calcinação }\end{array}$ & $\begin{array}{l}\text { Uso de tinta de baixa qualidade que contenha alta concentração de pigmentação; Uso externo } \\
\text { de tinta indicada para superfícies internas. }\end{array}$ \\
\hline $\begin{array}{l}\text { Desbotamento } \\
\text { prematuro ou } \\
\text { excessivo }\end{array}$ & $\begin{array}{l}\text { Uso externo de tinta indicada para superfícies internas; Uso de tinta de baixa qualidade, } \\
\text { culminando em rápida deterioração do filme; Uso de determinadas cores de tinta mais } \\
\text { suscetíveis aos raios UV (como tons de vermelho, azul e amarelo); Tingimento de tinta branca } \\
\text { não indicada para o processo ou dosagem excessiva de uma base clara ou média. }\end{array}$ \\
\hline $\begin{array}{l}\text { Baixa resistência ao } \\
\text { atrito }\end{array}$ & $\begin{array}{l}\text { Uso de tinta de baixa qualidade que seja muito porosa. } \\
\text { Aplicação de tinta em uma superfície que não tenha sido selada. }\end{array}$ \\
\hline $\begin{array}{l}\text { Baixa retenção de } \\
\text { brilho }\end{array}$ & $\begin{array}{l}\text { Uso externo de tinta indicada para superfícies internas; Uso de tinta de baixa qualidade; Uso } \\
\text { de tinta alto brilho base óleo ou alquídica em locais que recebem direta luz do sol; A } \\
\text { incidência luz do Sol diretamente sobre a superfície pode comprometer a emulsão e os } \\
\text { pigmentos da tinta, provocando a calcinação e perda de brilho. }\end{array}$ \\
\hline
\end{tabular}

Fonte: Polito (2006). 


\section{CONCLUSÕES}

Com base na revisão bibliográfica verificam-se que a maioria das pesquisas relacionadas ao estudo das manifestações patológicas visam as fachadas e as estruturas de concreto armado. Outros sistemas construtivos, tais como impermeabilizações, pinturas, pisos e esquadrias pouco são explorados.

No geral os estudos apontam como causas a falta ou inexistência das manutenções preventivas, poucos associam a inadequação ou erros de concepção de projetos de engenharia ou incompatibilidade entre os sistemas construtivos e os materiais.

Outra consideração trata da visão ainda macro em relevância aos fatores microscópicos quando se trata das anomalias construtivas. O ponto alvo ainda é o mapeamento de anomalias em macroescala, além das matrizes de correlação anomalias / causas prováveis.

Os estudos também apontam as condições de exposição e localização geográfica das edificações de forma a associar as anomalias aos fatores de danos. Desta forma, conclui-se que há necessidade de aplicar estudos multiescala no que se refere as anomalias construtivas, além de reconhecer que muitas das manifestações patológicas advêm da falta de projetos complementares e multidisciplinares entre si, que interajam os sistemas de forma conjunta e não isoladas.

\section{REFERÊNCIAS}

AMORIM, A.A. Durabilidade das Estruturas de Concreto Armado Aparentes. Monografia. Universidade Federal de Minas Gerais . Belo Horizonte. MG.2010

ASSOCIAÇÃO BRASILEIRA DE NORMAS TÉCNICAS. NBR 12655: Concreto de cimento Portland — Preparo, controle, recebimento e aceitação - Procedimento. Rio de Janeiro, 2015.

NBR 15575-1: Edificações Habitacionais — Desempenho Parte 1: Requisitos gerais. Rio de Janeiro, 2013.

BECERE, O.H. Revestimentos de ligantes sintéticos: proposta de métodos de ensaios para avaliação de desempenho. Dissertação. Instituto de Pesquisas Tecnológicas do Estado de São Paulo - IPT. Pós Graduação em Habitação: Planejamento e Tecnologia. São Paulo. 2007.

BRITEZ, A. A.Diretrizes para especificação de pinturas externas texturiza-das acrílicas em substrato de argamassa. Dissertação (Mestrado) - Escola Politécnica da Universidade de São Paulo. Departamento de Engenharia de Construção Civil. São Paulo. SP, 2007.

CABRAl, A.D.B.; CAMPOS, A.M.R. Estudo da Agressividade do Ar em Fortaleza/CE. Dissertação de mestrado. Universidade Federal do Ceará. Fortaleza.CE. 2016.

CIB W80. Guide and Bibliography to Service Life and Durability Research for Buildings and Components. CIB Publication 295, CIB, 2004.

FONTENELLE, M.; MOURA, Y. - "Revestimento cerâmico em fachadas - Estudo das causas das anomalias, Relatório de pesquisa", Comunidade da Construção, Fortaleza, 2004.

GASPAR, P. Vida útil das construções: desenvolvimento de uma metodologia para a estimativa da durabilidade de elementos da construção. Aplicação a rebocos de edifícios correntes. Tese (Doutorado). Engenharia Civil do Instituto Superior Técnico. Universidade Técnica de Lisboa, Lisboa, 2009.

ISO 6241:1984 - Performance standards in building -- Principles for their preparation and factors to be considered. 1984.

LERSCH, I.M. Contribuição para identificação dos principais fatores e mecanismos de degradação em edificações do patrimônio cultural de Porto Alegre. Dissertação (mestrado). Universidade Federal do Rio Grande do Sul. Porto Alegre. RS. 2003. 
LUCAS, J.; ABREU, M. - "Revestimentos cerâmicos colados - descolamento”, ICTPRC-4, LNEC, Lisboa, 2006.

OLIVEIRA, L. A. de; SAHADE, R. F.; VARELlA, L. A. M.; TEIXEIRA, E.S. L. Incidência de Descolamento em Revestimentos Cerâmicos Aderidos em Fachadas: Contribuição para o Projeto e a Produção. $1^{\circ}$ Workshop de Tecnologia de Processos e Sistemas Construtivos TECSIC - 2017. Universidade Estadual de Campinas - Unicamp)Campinas. SP.2017.

OLIVEIRA, V.C; BAUER, E.; OLIVEIRA, M.J; CARVALHO, M.T.; HENRIQUE, E. Os fenômenos de pré - danos nas fachadas dos edifícios - conceituação e aplicação. Anais do Congresso Brasileiro de Patologia das Construções CBPAT 2016. Belém. Pará. 2016.

POLITO, G. Principais Sistemas de Pinturas e suas Patologias. Apostila do Departamento de Engenharia de Materiais e Construção. Universidade Federal de Minas Gerais. Belo Horizonte. MG. 2006

RODRIGUES, F.A.C.S. Modelos de gestão da degradação de infraestruturas portuárias. Dissertação (mestrado). Universidade Técnica de Lisboa. Lisboa. Portugal. 2011.

SANTOS, M.J.B.O. Catalogação de patologias em fachadas de edifícios residenciais de Brasília. Dissertação (mestrado). Universidade de Brasília, 2017.

SILVA, M. N. B. Avaliação quantitativa da degradação e vida útil de revestimentos de fachada - aplicação ao caso de Brasília.DF. Tese (Doutorado) Universidade de Brasilia, 2014.

SILVA, P. F. A. Durabilidade das Estruturas de Concreto Aparente em Atmosfera Urbana. São Paulo: Editora Pini, 1995.

SILVESTRE, J. Sistema de Apoio à Inspeção e Diagnóstico de Anomalias em Revestimentos Cerâmicos Aderentes. Dissertação de Mestrado, Instituto Superior Técnico, Universidade Técnica de Lisboa, Lisboa, Portugal, 2005 .

SOUSA, R.D.B. Previsão da Vida Útil dos Revestimentos Cerâmicos Aderentes em Fachada. Dissertação de Mestrado, Instituto Superior Técnico, Universidade Técnica de Lisboa, Lisboa, Portugal, 2008.

SOUZA, R. B.. Suscetibilidade de pastas de cimento ao ataque por sulfatos - método de ensaio acelerado. São Paulo, Dissertação de Mestrado. Escola Politécnica da Universidade de São Paulo. São Paulo. SP 2006.

SOUZA, R. B.; REBOITA, M. S.; WERLE, A. P.; COSTA, E. B. C. Influência das variáveis atmosféricas na degradação dos Materiais da construção civil. REEC - Revista Eletrônica de Engenharia Civil Vol $13-n^{\circ} 1$. Universidade Federal de Goiás. 2016.

SOUZA, V. C.; RIPPER, T. Patologia, recuperação e reforço de estruturas de concreto. São Paulo: Pini, 1998.

TEIXEIRA, BC.; SILVA, A.J.C. Elaboração de mapa de danos de prédio histórico: um estudo de caso em fachadas com revestimento em pintura da Escola Politécnica da Universidade de Pernambuco. Revista de Engenharia e Pesquisa Aplicada. v. 4, n. 4, p.10,2019

VIDAL, É. C.Avaliação de patologias em conjuntos habitacionais de bauru, com enfoque em anomalias de fundações e de coberturas. Dissertação de Mestrado - Universidade Estadual de Campinas, Faculdade de Engenharia Civil, Arquitetura e Urbanismo. Campinas, SP. 2012.

ZUCCHETTI, L. Influência das Características do Peitoril no Molhamento dos Paramentos Próximos às Janelas Frente à Chuva Dirigida. Tese. Universidade Federal do Rio Grande do Sul. Porto Alegre. RS. 2016. 